\title{
ОСНОВНЫЕ ЭТАПЫ РАЗВИТИЯ НАУЧНЫХ ПРЕДСТАВЛЕНИЙ ОБ ИСПОЛЬЗОВАНИИ ОБЪЕКТОВ ВОЛОКНИСТОЙ ПРИРОДЫ И ИЗДЕЛИЙ ИЗ НИХ В КРИМИНАЛИСТИКЕ БЕЛАРУСИ
}

\author{
Панченя Д.Н. \\ Государственный комитет судебных экспертиз Республики Беларусь, \\ 2. Минск, Беларусь
}

Современное состояние и перспектива развития судебно-экспертной деятельности в Республике Беларусь невозможно представить без анализа и учета теоретико-правового наследия использования специальных знаний об объектах волокнистой природы и изделий из них в отечественной криминалистике.

В статье дается ретроспективный анализ теоретических, правовых и практических аспектов деятельности сведущих лич в период с XIX в. и до настоящего времени по обнаружению, изъятию и экспертному исследованию волокнистых изделий и их следов, $a$ также применению полученных результатов в расследовании преступлений.

Ключевые слова: этапы развития, криминалистика, объекты волокнистой природы и изделия из них, текстильные волокна, исследование, судебная экспертиза, эксперт.

Проблема использования специальных знаний о различных материальных объектах в судебноэкспертной деятельности в целях расследования преступлений уходит к далекому прошлому, имеет богатую историю и сохраняет свою актуальность в настоящее время. Возникновение и становление научных представлений об использовании объектов волокнистой природы и изделий из них (далее - объекты волокнистой природы) в экспертной, следственной и судебной практике на территории Беларуси в период с XIX в. до настоящего времени проходило в рамках развития криминалистики Российской империи (до 1917 г.), БССР (до 1991 г.) и Республики Беларусь (до настоящего времени), что обусловлено особенностями геополитических, социальноэкономических и общественных отношений на указанных этапах исторического развития нашего государства.

Анализ литературных источников показал, что изучение данного вопроса целесообразно начинать с XIX в., когда происходит стремительный рост интереса ученых к следственной и судебной деятельности в Российской империи, в состав которой на тот момент входили территории современной Беларуси. Это в значительной степени связано с публикациями Н. Орлова, Я.И. Баршева, Е. Колоколова, В.Д. Спасовича, В.А. Линовского, И.Я. Фойницкого, в работах которых рассматривались вопросы тактики и методики проведения различных следственных действий, обнаружения и изъятия разного рода вещественных доказательств.

Эпизодические упоминания об объектах волокнистой природы содержатся в трудах судебных медиков, например, в «Правилах для врачей при судебно-медицинском осмотре и вскрытии мертвых тел» (1829 г.), в учебниках С.А. Громова «Краткое изложение судебной медицины для академи-

\footnotetext{
Адрес для корреспонденции: Панченя Дмитрий Николаевич, начальник отдела исследования и учетов объектов животного происхождения и волокнистой природы управления генотипоскопического учета главного управления специальных экспертиз Центрального аппарата Государственного комитета судебных экспертиз Республики Беларусь, 220073, ул. Кальварийская, д. 43; г.Минск, Республика Беларусь тел./ракс: +375 1730863 26, e-mail: fibers@sudexpert.gov.by
} 
ческого и практического употребления» (1832 г.). В работе Г.И. Блосфрельда «Начертание судебной медицины для правоведов» (1847 г.) изложены сведения, касающиеся порядка судебно-медицинского исследования трупа, согласно которого параллельно с повреждениями тела человека изучались повреждения его предметов одежды в качестве сопутствующих факторов, представляющих дополнительную информацию для правильной диагностики повреждений тела [1].

Первой попыткой законодательного регулирования деятельности «сведущих людей», а также правил «исследования происшествий и осмотров" в дореволюционном уголовном процессе является принятие в 1832 г. Свода законов Российской империи. Именно с момента его появления формируется представление о действии, сходном с современной экспертизой, и деятельности эксперта в ее нынешнем понимании [2]. Характерной особенностью проводимых в анализируемый период экспертных исследований является то, что поступающие сведущим лицам объекты изучались с использованием методов, непосредственно заимствованных из базовых областей знаний, при этом научного обоснования сделанных выводов не требовалось.

Несмотря на возникший интерес со стороны ученых-криминалистов к различным материальным объектам как источнику доказательств, российское уголовное судопроизводство вплоть до судебной реформы 1864 г. изучению косвенных доказательств (улик) отводило весьма незначительную роль. Ситуация изменилась в связи с проведением вышеупомянутой реформы в России и принятием в 1864 г. Устава уголовного судопроизводства. С развитием теории доказательств суды стали запрашивать от сведущих лиц описание всего процесса исследования с указанием проводимых действий, обоснованием выводов, перечислением методов, которые использовались при проведении экспертизы, что позволило судьям оценивать заключения экспертов [3]. В результате был отменен формальный подход к оценке доказательств и значительно вырос интерес к использованию результатов их исследования, в связи с чем они все чаще стали фигурировать в уголовном процессе. Этому в немалой степени способствовали примеры успешных исследований в рамках проведения экспертиз, которые осуществляли ведущие ученые-химики Санкт-Петербургской Академии наук Ю.Ф. Фрицше, Ю.К. Трапп, Д.И. Менделеев, Н.Н. Зинин, Е.В. Пеликан и др. [4].

Приведем один из ярких примеров использования знаний сведущих лиц в области исследования волокнистых материалов. В 1860 г. на Ростовской ярмарке произошло возгорание партии бумажной пряжи. Сотрудниками полиции у купцов, торговавших этим товаром, были изъяты образцы пряжи, предоставленные впоследствии в Медицинский департамент Министерства внутренних дел. По итогам исследования был сделан вывод, согласно которому причиной возгорания пряжи явился ее красный цвет, способствующий поглощению кислорода из воздуха, что «в состоянии произвести возвышенную температуру, достаточную для воспламенения». После дачи такого заключения властями были приняты строгие меры: в Ростове запретили продажу красной хлопчатобумажной пряжи. Спустя годы ростовские купцы, неся значительные убытки, обратились в Сенат с прошением об отмене запрета. В 1870 г. вопрос вторично рассматривался Медицинским советом. Комиссия, в состав которой вошли профессора Д.И. Менделеев, Е.В. Пеликан и Ю.К. Трапп, собрала подробные сведения о способах крашения текстильных материалов, затребовала и изучила образцы пряжи из разных губерний Российской Империи, после чего вынесла следующее решение: «Способность бумажной пряжи и тканей к самовоспламенению не зависит от окраски их в какой-либо цвет, но зависит от присутствия в них излишнего количества жира (особенно рыбьего - ворвани), не удаленного после окраски. 
Опасность самовоспламенения значительно возрастает в случае, если фабриканты добавляют рыбий жир в готовую продукцию для привеса и увеличения своих доходов» [5].

Рассматривая все возрастающее значение для судопроизводства сведений, получаемых в ходе исследования объектов волокнистой природы, следует отметить мнение известного российского юриста А.А. Квачевского о микроскопических следах текстильных изделий - волокнах. В своей работе «Об уголовном преследовании, дознании и предварительном исследовании преступлений по уголовным уставам 1864 г.» (1967 г.) ученый писал: «Одним из лучших указателей на известное лицо служат ... следы разных мелких вещей» [6].

Следует отметить, что в конце XIX - начале XX вв. фрормированию научных представлений об использовании знаний об объектах волокнистой природы в процессе расследований преступлений способствовали труды зарубежных авторов, в первую очередь Г. Гросса, Г. Поппа и Р.А. Рейса [7]. Изложенные в них первые обобщенные криминалистические знания о текстильных материалах и их следах, а также яркие примеры из практики раскрытия преступлений послужили основой для собственных работ Л.Е. Владимирова, С.Н. Трегубова, В.И. Лебедева, Б.Л. Бразоля.

Наряду с развитием теоретической, практической базы по использованию объектов волокнистой природы и результатов их экспертного исследования в уголовном судопроизводстве начали формироваться первые судебно-экспертные органы. Огромное значение имело создание в 1912 г. Кабинета научно-судебной экспертизы при прокуроре Санкт-Петербургской судебной палаты, а также аналогичных кабинетов в Москве, Киеве и Одессе, открытых спустя два года. В Законе "Об учреждении кабинета научно-судебной экспертизы» от 28.06.1912 впервые упоминается о возможности проведения экспертных исследований методами химического и микроскопического анализа [8].

Существенный вклад в разработку научных методов исследования объектов волокнистой природы внес основатель Кабинета научно-судебной экспертизы в Харькове, судебный медик, профессор Н.С. Бокариус. В 1910 г. вышла в свет его первая монография «Судебно-медицинские микроскопические и микрохимические исследования вещественных доказательств», ставшая на долгие годы настольной книгой для криминалистов. В главе $\mathrm{VI}$ «Об исследовании характера некоторых тканей» приведены методы макро- и микроскопического исследований волокон льна, хлопка, шелка, описано их строение, даны иллюстрации. Глава VII «Добавления» содержит подробное описание устройства микроскопа, а также образцы актов микроскопических и микрохимических судебно-медицинских исследований, структура которых почти полностью совпадает с современным заключением эксперта [1]. Большое значение для криминалистики имеет разработка Н.С. Бокариусом теоретических и методических основ экспертных исследований повреждений одежды, изготовленной из текстильных материалов. Ученым была предложена классификация и даны первые методические рекомендации по проведению предварительного исследования повреждений одежды: необходимость указания локализации повреждений, точного их описания с указанием формы, размеров, конфригурации краев, сопоставление с повреждениями на теле человека [9].

Таким образом, в дореволюционной России научные сведения об использовании объектов волокнистой природы в расследовании преступлений чаще всего заимствовались из зарубежных источников, фракты их экспертного исследования носили эпизодический характер и осуществлялись в основном в рамках производства судебно-медицинских экспертиз. Наряду с этим шло образование первых экспертных учреждений, подбор и подготовка сотрудников, 
применявших полученные специальные знания на практике. Накопленный на тот момент научный и эмпирический материал об объектах волокнистой природы, тактических приемах и средствах обнаружения и изъятия, разработка методов их исследования в дальнейшем стимулировали ученых-криминалистов к разработке теоретического фундамента судебной экспертизы волокнистых материалов и изделий из них и использования ее результатов в расследовании преступлений.

Второй этап становления научной и практической экспертной деятельности по изучению объектов волокнистой природы в Беларуси начинается в 1917 г. и связан с созданием Советского государства. Он характеризуется распадом старой дореволюционной системы органов юстиции, следственных и оперативно-розыскных органов, созданием и развитием сети новых судебноэкспертных учреждений. Этот процесс происходил на фоне обобщения экспертной практики проведения судебных экспертиз, разработкой их научно-методических положений, фрормирования научных основ криминалистической техники, в которых происходила консолидация и развитие знаний о системе средств и методов обнаружения, фиксации, изъятия и исследования объектов волокнистой природы [5].

Согласно исследованию, проведенному В.П. Ивановым и М.С. Штейнгаузом, в послереволюционный период на территории Беларуси почти отсутствовали условия, необходимые для развития научных основ экспертной деятельности: не было высших учебных заведений и научно-исследовательских институтов, а деятельность экспертов опиралась на практический опыт России и Украины [10]. По этой причине огромное значение в становлении экспертнокриминалистической службы страны имело образование первых белорусских экспертных учреждений: судебно-медицинского отделения при Центральной химико-бактериологической станции Народного комиссариата здравоохранения БССР (1921 г.) и Института научно-судебной экспертизы при Народном комиссариате юстиции БССР (1929 г.). В 1931 г. была образована Центральная судебно-медицинская лаборатория Народного комиссариата здравоохранения БССР, а при Управлении милиции НКВД БССР было организовано научно-техническое отделение в составе эксперта-химика И. Левина, которое было оснащено оборудованием для химической лаборатории. Представляется, что именно с этого времени становится возможным проведение химических экспертиз в системе МВД БССР.

Изучение научной литературы послереволюционного периода позволяет сделать вывод о том, что научные работы по исследованию объектов волокнистой природы все чаще появлялись в различных отраслях знаний: в зоологии, ботанике, химии, фризике, медицине, текстильной промышленности. Представляют определенный интерес труды реставраторов и археологов по изучению особенностей изготовления и технологии крашения «археологического текстиля", обнаруживаемого в ходе раскопок курганов, могильников и мест захоронений, кладов. Разработанные учеными-историками подходы к исследованию поврежденных текстильных материалов нашли применение в криминалистике в целях решения ряда реставрационных задач. В частности, сотрудник Оружейной палаты Московского Кремля В.К. Клейн, имея богатый опыт лабораторного исследования текстильных материалов, сформировал научный подход к изучению музейных тканей, Н.Л. Шабельская занималась технологиями древнерусского шитья, В.Н. Кононов изучал красители древних тканей, сходные проблемы решали А.А. Воскресенский, Н.П. Тихонов.

В рассматриваемый период времени появляются следующие отечественные работы 
по изучаемой тематике: П. Геерман «Механические и фризико-технические текстильные исследования» (1930 г.) и «Текстильно-химические исследования» (1933 г.), А.П. Закопщиков «Текстильная микроскопия» (1931 г.), Н.Я. Демьянов и В.В. Феофилактов «Химия растительных веществ» (1933 г.), М.С. Магитт «Микроскопия лубяных растений» (1938 г.). Изложенные в них сведения о классификации, строении, химическом составе, основных фризико-химических свойствах, способах технологической обработки и крашения, различных методах исследования волокнистых материалов впоследствии были успешно заимствованы экспертами для решения собственных специфических задач.

В 1930 - 1940-е гг. появляются работы, в которых наблюдается стремление криминалистов выделить определенные закономерности проведения экспертных исследований, систематизировать знания в данной области, сформировать собственные методы исследования. В результате выходят в свет первые научные статьи по криминалистическому исследованию волокнистых материалов и изделий из них: С.Д. Каплан «Идентификация волокон и ткани растительного происхождения» (1936 г.) и «Основные принципы исследования хлопчатобумажных тканей» (1948 г.), К.О. Завадинской «О судебном исследовании растительных волокон» (1938 г.) и «Идентификация тканей» (1947 г.), А.Г. Архангельского «Учение о волокнах» (1938 г.) и «Швейное материаловедение» (1946 г.).

Таким образом, на данном этапе постепенно увеличивается потребность в получении достоверных научных сведений о текстильных материалах в различных сфрерах деятельности человека, в связи с чем происходит дальнейшее совершенствование уже существующих и внедрение новых методов их исследования. Изучение морфологических и структурных свойств объектов волокнистой природы, технологических особенностей их изготовления и обработки существенно расширили круг вопросов, решаемых в ходе экспертизы, что привело к их более частому включению в процесс раскрытия и расследования преступлений.

Третий, послевоенный этап использования специальных знаний об объектах волокнистой природы в криминалистике Беларуси связан с деятельностью эксперта химико-биологического отделения УМ МВД БССР З.И. Сычевой - автора многих статей и научных разработок в области криминалистического исследования волокнистых материалов, наиболее значимые из которых: «Установление групповой принадлежности текстильных волокон с помощью красителей и реактивов» (1963 г.), «Поляризационно-микроскопическое исследование текстильных волокон» (1965 г.), «Экспертное исследование минерального состава некоторых волокнистых материалов» (1968 г.), «Экспресс-метод определения химических волокон по интерференционному окрашиванию в поляризованном свете» (1970 г.). В 1968 г. 3.И. Сычева защитила диссертацию на тему: “Оптические методы идентифрикации химических волокон». Представляют особый интерес также совместные работы с В.Т. Сергеенко в области разработки методов распознавания волокнистых материалов и криминалистического исследования химических волокон.

В целом необходимо отметить, что до 1970 г. исследование объектов волокнистой природы осуществлялось преимущественно в рамках судебно-химической экспертизы [12]. Отдельные вопросы по данному направлению изучались в рамках трасологических, товароведческих, материаловедческих и судебно-биологических экспертиз. При этом в ходе проведения различного рода и вида экспертиз в отношении волокнистых материалов и текстильных волокон решались одни и те же задачи. Исследование микрочастиц текстильных волокон, обнаруживаемых на орудиях преступления, теле человека и в повреждениях, проводились судебно-медицинскими 
экспертами, которые внесли существенный вклад в разработку частных методик обнаружения волокон, их изъятия и последующего сравнительного исследования [13].

В рамках судебно-медицинских и трасологических экспертиз исследовались повреждения предметов одежды различными орудиями, которые в совокупности с повреждениями на теле человека позволяли отождествлять искомое орудие. Экспертами устанавливались волокнистый состав поврежденных текстильных материалов и характерные черты их разрушения, используемые впоследствии при решении задачи отождествления целого по его частям. В ходе проведения товароведческих и материаловедческих экспертиз также решались специфические задачи в соответствии с предметом каждой из них: установление природы волокон, определение волокнистого состава текстильных материалов, исследование красителей, установление технологических параметров и соответствие их государственным стандартам [14].

Одним из родоначальников судебной экспертизы волокнистых материалов и изделий из них в Беларуси по праву является А.3. Малинникова, которая в феврале 1975 г. начала свою деятельность в Научно-исследовательском институте судебной экспертизы Министерства юстиции БССР. В 1979 г. ей первой была присвоена квалификация судебного эксперта по специальности «Исследование волокнистых материалов и изделий из них». Имея стаж экспертной и научной работы более 40 лет, на протяжении всей трудовой деятельности А.З. Малинникова активно занималась практической и научно-исследовательской работой, подготовкой экспертовволокноведов. Ею опубликовано, в том числе и в соавторстве, более 50 работ по использованию специальных знаний об объектах волокнистой природы в процессе расследования преступлений, среди которых имеются научные статьи, тезисы, справочные, методические пособия, методические рекомендации для оперативных работников, следователей, судей и экспертов.

В лаборатории криминалистических экспертиз материалов, веществ, изделий и биологических исследований НИИСЭ Министерства юстиции БССР в 80-х гг. создается коллектив экспертовволокноведов, которые не только проводили судебные экспертизы, но и осуществляли научную деятельность в различных направлениях: 3.И. Сычева, Т. Алимпиева, В.А. Позняк, А.Ф. Корф, Н.В. Перевозникова, Е.П. Асташинская, Л.А. Карпусь, Е.А. Капитанова, В.П. Чернов, О.Л. Пономарева, Н.В. Герман, А.А. Лазарь, И.П. Ахрамович, А.З. Малинникова. В связи с возросшей потребностью правоохранительных органов в результатах исследования объектов волокнистой природы численность сотрудников лаборатории, работающих в данном направлении, в течение многих лет составляла не менее семи экспертов. Отдельно необходимо отметить научную и практическую деятельность В.П. Чернова, публикации которого на тему исследования свойств оптической анизотропии легли в основу разработки методики дифференциации текстильных волокон.

Особую роль в становлении судебной экспертизы волокнистых материалов и изделий из них на различных этапах ее развития внесли руководители и сотрудники НИИСЭ Министерства юстиции БССР А.В. Дулов, Г.И. Грамович, Н.И. Порубов, О.М. Дятлов, И.С. Андреев, В.П. Иванов, Н.И. Николайчик, А.С. Рубис, Л.А. Шукан, А.Г. Михайленко.

Следует отметить главную характерную особенность в организации проведения судебной экспертизы волокнистых материалов и изделий из них в Беларуси в рассматриваемый период - данная деятельность осуществлялась экспертами Министерства юстиции БССР и Министерства внутренних дел. При этом активные научные разработки в данной области, а позднее и экспертизы Министерством юстиции регулярно проводились уже с 1975 г., после 
создания сектора исследования материалов, веществ и изделий. В системе МВД развитие рассматриваемого вида экспертиз получило мощный толчок лишь к концу 80-х гг. До этого времени работа в ведомстве с объектами волокнистой природы была направлена в основном на их обнаружение и изъятие в ходе проведения осмотров мест происшествий, последующее их исследование в рамках судебных экспертиз.

Четвертый этап развития научных представлений об использовании волокнистых материалов и изделий из них в отечественной криминалистике начался в 1991 г. Он связан прежде всего с происходившими в стране геополитическими изменениями, а также с прекращением существования действующей советской системы судебно-экспертных учреждений. В июне 1993 г. была проведена структурная реорганизация экспертной службы: при МВД Республики Беларусь был создан Научно-криминалистический центр, а в экспертно-криминалистическом управлении МВД образованы два отдела [10]. В состав отдела специальных исследований Научно-криминалистического центра вошла специализированная лаборатория по исследованию волокнистых материалов и изделий из них. С этого времени судебные экспертизы волокнистых материалов и изделий из них в системе МВД Беларуси проводятся на регулярной основе, а их число с каждым годом увеличивается.

В последующее десятилетие, пройдя ряд преобразований (в 1994, 1996, 2000 и 2001 гг.), на базе лаборатории по исследованию волокнистых материалов и изделий из них создается отдел исследования микрообъектов, входящий в структуру девятого управления Государственного экспертно-криминалистического центра МВД Республики Беларусь. С начала 2000-х гг. экспертами отдела ежегодно выполнялись сотни судебных экспертиз и исследований, на постоянной основе осуществлялось техническое сопровождение следственно-оперативных групп по расследованию тяжких и особо тяжких преступлений, велась подготовка экспертовволокноведов территориальных подразделений областного уровня.

Существенные изменения в начале 1990-х гг. затронули и НИИСЭ Министерства юстиции БССР, который до 2013 г. носил название государственное учреждение «Центр судебных экспертиз и криминалистики Министерства юстиции Республики Беларусь». Сотрудниками отдела проводились наиболее сложные экспертизы, выполнялись научные разработки по совершенствованию тактики проведения следственных действий и методики расследования отдельных видов преступлений, организации и проведению экспертных исследований волокнистых материалов, а также были подготовлены ряд методических и справочных пособий для экспертов, научных статей и информационных писем.

В период 1990 - 2000 гг. продолжилось изучение объектов волокнистой природы, в частности, принципиальных возможностей применения различных методов (оптических, химических, хроматографических, инструментальных, аналитических), материалов и оборудования для исследования окрашенных текстильных волокон, пряжи, тканей. Возникает необходимость адаптации существующих и разработки современных частных методик изучения новых образцов текстильных материалов.

Развитию теоретических положений и практических разработок в области экспертного исследования текстильных материалов способствовали работы таких ученых и специалистовпрактиков, как И.А. Синькевич, Н.И. Сасункевич, Н.В. Сидоренко, Ж.В. Малинок, Г.В. Мельникова, А.А. Ивашкевич и др. Ими были сформулированы основные теоретические положения криминалистического исследования волокнистых материалов и изделий из них, 
разработаны наиболее эфффективные приемы и способы их обнаружения и изъятия в ходе проведения следственных и иных процессуальных действий, рассмотрены вопросы методики экспертного исследования этих объектов и их следов и т.д.

Пятый этап развития представлений об использовании объектов волокнистой природы отечественной криминалистике связан с образованием Государственного комитета судебных экспертиз, отсчитывающего свою историю с 22 апреля 2013 г. - дня подписания Президентом Республики Беларусь А.Г. Лукашенко Указа №202 «Об образовании Государственного комитета судебных экспертиз Республики Беларусь». Созданное на базе существовавших в стране государственных судебно-экспертных учреждений единое экспертное ведомство начало свою работу 1 июля 2013 г.

В рассматриваемый период была проведена модернизация химической лаборатории отдела исследования микрообъектов, что позволило значительно расширить возможности подразделения по исследованию поступающих вещественных доказательств, а также выйти на качественно новый уровень проведения судебных экспертиз. Отдел оснащен микроскопом «Nikon Eclipse 50i», использование которого в сравнении с имевшимися в подразделении более простыми по конструкции и уже морально устаревшими микроскопами «ПОЛАМ ЛМПР» позволяет изучать текстильные волокна и сопутствующие материалы современными методами оптической микроскопии: световой, фазово-контрастной, интерференционной, поляризационной, люминесцентной.

Научные разработки в области криминалистического исследования объектов волокнистой природы продолжают вестись в ГУ «Научно-практический центр Государственного комитета судебных экспертиз Республики Беларусь», в котором до 2017 г. работали научные сотрудники лаборатории исследования материалов, веществ и изделий А.З. Малинникова и И.П. Ахрамович, А.И. Гринь, В.А. Будевич, А.А. Коляда. Одними из последних трудов ученых являются «Методические рекомендации по криминалистическому исследованию хлопковых текстильных волокон» (2017г.) и «Методические рекомендации по криминалистическому исследованию текстильных волокон с использованием спектроскопии комбинационного рассеяния света» (2020 г.).

Современный этап развития научных представлений об использовании объектов волокнистой природы в Республике Беларусь связан с реорганизацией отдела исследования микрообъектов и образованием отдела исследования и учетов объектов животного происхождения и волокнистой природы управления генотипоскопического учета, входящего в структуру главного управления специальных экспертиз центрального аппарата Государственного комитета. Характерной особенностью нового подразделения, начавшего свою деятельность с октября 2020 г., является проведение двух видов судебных экспертиз: волокнистых материалов и изделий из них, а также судебной биологической экспертизы.

Для успешного выполнения поставленных задач в области проведения судебных экспертиз волокнистых материалов и изделий из них лаборатория отдела оснащена ИК-Фурье микроскопом «Nicolet iN10», поляризационным микроскопом «ПОЛАМ Л-213М» и иным современным оборудованием. На сегодняшний момент лаборатория по многим параметрам (особенности конструкции, освещение, вентиляция, качество лабораторной мебели, техническое оснащение) соответствует международным стандартам качества проведения судебных экспертиз в области криминалистического исследования волокнистых материалов и изделий из них. Ежегодно в 
лаборатории подвергается исследовано более полутора тысяч вещественных доказательств и около семи тысяч образцов сравнения в рамках расследования преимущественно тяжких и особо тяжких преступлений, а также преступлений, имеющих общественный резонанс. В лаборатории осуществляется комплексный осмотр вещественных доказательств в случаях проведения сложных многообъектных экспертиз с участием судебных экспертов других специальностей: трасологов, биологов, товароведов и др.

В заключение стоит отметить, что в настоящее время в Республике Беларусь создана оптимальная структура судебно-экспертных подразделений с эффрективно функционирующей системой проведения судебных экспертиз волокнистых материалов и изделий из них. На планомерной основе осуществляется разработка и внедрение новых методик экспертных исследований, а также методов, приемов и средств обнаружения, изъятия и фиксации объектов волокнистой природы, совершенствуются вопросы, связанные с назначением судебных экспертиз государственными органами, обеспечивается единство методологии волокноведческих исследований, осуществляется подготовка высококвалифицированных экспертных кадров. Эксперты-волокноведы принимают участие в различных международных мероприятиях, проектах, программах стажировок, на базе центрального аппарата организуются и проводятся учебные мероприятия в рамках профессиональной подготовки экспертов-волокноведов. В целях совершенствования судебно-экспертной деятельности, ознакомления с техническими возможностями изъятия и исследования объектов волокнистой природы, обмена опытом сотрудниками отдела за последние годы осуществлены стажировки в КНР, Хорватии, Франции. Налажены тесные контакты с экспертными учреждениями стран ближнего зарубежья - Россией, Украиной, Молдовой, Казахстаном, Узбекистаном.

На основании вышеизложенного можно сделать заключение о том, что развитие научных представлений о роли объектов волокнистой природы в процессе расследования преступлений на территории Беларуси происходило в пять этапов:

1) Дореволюционный (начало XIX в. - 1917 г.), характеризующийся единичными фактами использования объектов волокнистой природы в криминалистике, заимствованием научных знаний из зарубежных источников, накоплением научного и эмпирического материала о методах и средствах обнаружения, образованием первых экспертных учреждений;

2) Послереволюционный (1917 - 1941 гг.), для которого свойственно формирование и развитие первых советских судебно-экспертных учреждений, разработка общих методов исследования в рамках судебно-медицинских и криминалистических экспертиз, разработка и внедрение научно-технических средств обнаружения, изъятия и фиксации объектов волокнистой природы;

3) Послевоенный (1945 - 1991 гг.), в ходе которого происходит создание и дальнейшее реформирование разрушенных в годы Великой Отечественной войны научных и практических судебно-экспертных учреждений в рамках Министерства юстиции и МВД БССР, образование специализированной лаборатории по исследованию объектов волокнистой природы, появление первых научных работ в данной области, разработка собственных методов исследования в рамках судебной экспертизы волокнистых материалов и изделий из них;

4) Постсоветский (1991 - 2013 гг.), в течение которого наблюдается создание и структурные преобразования первых в суверенной истории Беларуси судебно-экспертных учреждений, появляются научные разработки, касающиеся отдельных вопросов криминалистического 
исследования волокнистых материалов, совершенствуется материальное и научно-методическое оснащение территориальных экспертных подразделений в целях повышения эффективности использования специальных знаний в процессе обнаружения и изъятия объектов волокнистой природы в ходе осмотров мест происшествий;

5) Современный (2013 г. - по настоящее время), отсчитывающий свое начало со дня образования Государственного комитета судебных экспертиз Республики Беларусь - единого государственного экспертного органа, характеризующийся совершенствованием регламентации судебно-экспертной деятельности, модернизацией научно-технических средств поиска, обнаружения, фриксации и изъятия объектов волокнистой природы, внедрением современных методов их экспертного исследования, осуществлением на высоком уровне профессиональной подготовки сотрудников, развитием международного сотрудничества экспертов-волокноведов.

\section{Список литературы}

1. Роль профессора Н. С. Бокариуса в развитии судебной экспертизы и криминалистики / Цымбал М. Л., Симакова-Ефремян Э. Б., Дереча Л. Н. / Теорія та практика судової експертизи і криміналістики: збірник наукових праць. Вип. 9 / ред. кол.: М. Л. Цимбал, В. Ю. Шепітько, Л. М. Головченко та ін. - Х.: Право, 2009 - С. 566-574.

2. Исаева, Л.М. Специалист в уголовном судопроизводстве / Л.М. Исаева ; МВД Рос. Федерации, Всерос. науч.-исслед. ин-т. - М.: ВНИИ МВД России. 2004. - 95 с.

3. Орехова, Е. П. Становление и развитие судебной экспертизы / Е. П. Орехова // Вопросы криминологии, криминалистики и судебной экспертизы: сб. науч. тр. / Науч.-практ. центр Гос. ком. судеб. экспертиз Респ. Беларусь. - Минск, 2017. - Вып. 2. - С. 83-90.

4. Белкин, Р. С. История Отечественной криминалистики / Р. С. Белкин. - М.: Норма, 1999. - 486 с.

5. Россинская, Е. Р. История становления и развития института судебной экспертизы в России / Е. Р. Россинская, А. М. Зинин // Вестн. Ун-та им. О. Е. Кутафина. - 2015. - № 12. - С. 19-37.

6. 6. Квачевский, А. А. Об уголовном преследовании, дознании и предварительном исследовании преступлений по судебным уставам 1864 года: теорет. и практ. рук.: в 3 ч. / А. А. Квачевский. СПб.: Тип. Ф. С. Сущинского, 1866-1869. - Ч. 2: О дознании и розыске. - 1867. - [2], II, 371 с.

7. Торвальд, Ю. Следы в пыли: развитие судебной химии и биологии: пер. с нем. / Ю. Торвальд. - М.: Юрид. лит., 1982. - 174 с.

8. Хазиев, Ш. Н. К 100-летию первого российского закона о судебно-экспертной деятельности и судебной экспертизе / Ш. Н. Хазиев // Теория и практика судеб. экспертизы. - 2012. - № 4. - С. 141-150.

9. Бокариус Н. С. Судебная медицина для медиков и юристов / Н. С. Бокариус. - Х.: Юридич. изд-во Украины, 1930. - С.93-94.

10. Павлють, О.В. Деятельность эксперта-криминалиста органов внутренних дел в качестве специалиста при осмотре места происшествия / О.В. Павлють ; под ред. А.В. Дулова ; М-во внутр. дел Респ. Беларусь, учреждение образования «Акад. М-ва внутр. дел Респ. Беларусь». - Минск: Акад. МВД, 2012. - 162 с.

11. Дулов А.В. Краткий обзор научно-исследовательской деятельности НИИ судебной экспертизы Министерства юстиции Республики Беларусь. Вопросы криминологии, криминалистики и судебной экспертизы 2009. №2 (26), С.34-47.

12. Соколов, С. М. Судебно-химическая экспертиза материалов документов, копоти выстрела, волокнистых веществ и других вещественных доказательств / С. М. Соколов. - М.: Медицина, 1964. -311 c.

13. Еранов, Н. В. К методике приготовления препаратов текстильных волокон, обнаруженных на орудиях механической травмы / Н. В. Еранов // Вопросы судебно-медицинской экспертизы и 
криминалистики: сб. науч. ст. / Горьк. гос. мед. ин-т. - Горький, 1970. - Вып. 3. - С. 23-26.

14. Криминалистическое исследование волокнистых материалов и изделий из них: метод. пособие для экспертов: в 5 вып. / Всесоюз. науч.-исслед. ин-т судеб. экспертиз; редкол.: В. А. Пучков (гл. ред.) [и др.]. - М.: ВНИИСЭ, 1983. - Вып. 1: Научные основы и общие положения криминалистического исследования волокнистых материалов и изделий из них. - 161 с.

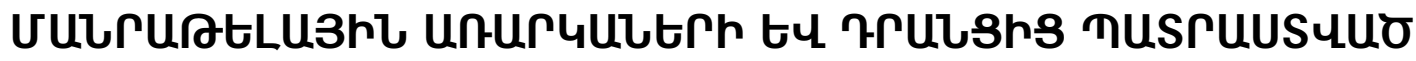

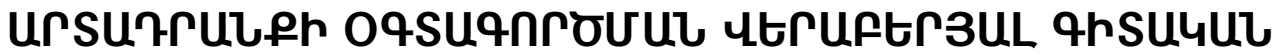

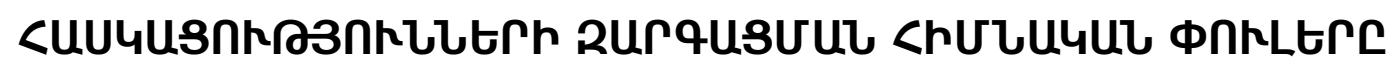 ftLUnกhUh คrtuqhSחhळ3nhunhU
}

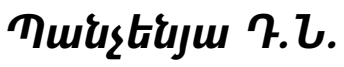

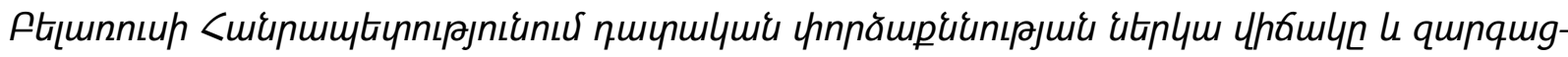

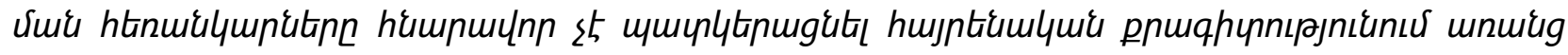

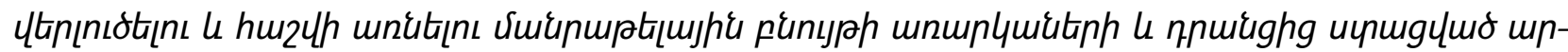

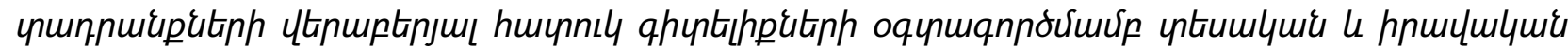
dunuiqqnıpnıนu:

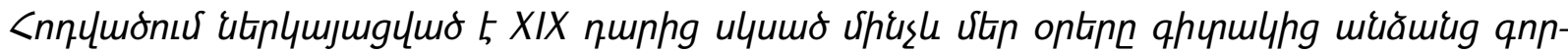

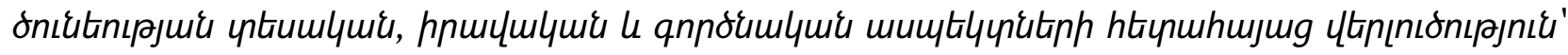

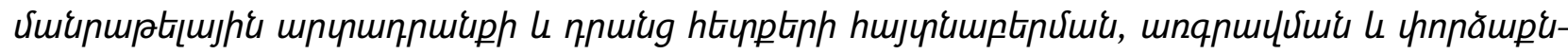

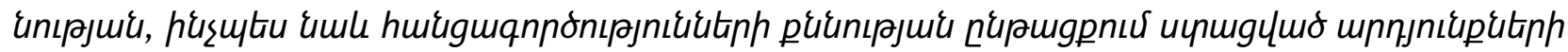
oqumannoriui ytinuptipjul:

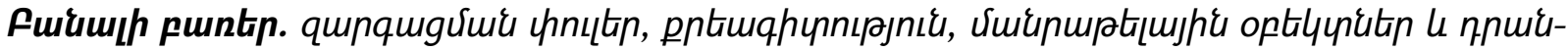

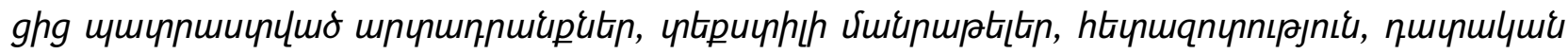

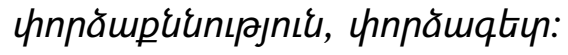

\section{THE MAIN STAGES OF THE DEVELOPMENT OF SCIENTIFIC IDEAS ON THE USE OF OBJECTS OF FIBROUS NATURE AND PRODUCTS THEREOF IN FORENSIC SCIENCE OF BELARUS}

\section{Panchenya D.N.}

The current state and prospects for the development of forensic activities in the Republic of Belarus cannot be imagined without analyzing and taking into account the theoretical and legal heritage of the use of special knowledge about objects of fibrous nature and products thereof in national forensic science.

The article provides a retrospective analysis of the theoretical, legal, and practical aspects of the activities of knowledgeable people, in the period from the 19th century and so far, on detection, seizure and forensic research of fibrous products and their traces, as well as the application of the results obtained in crime investigations.

Keywords: stages of development, forensic science, objects of fibrous nature and products thereof, textile fibers, research, forensic expertise, expert. 